\title{
Posture and scapular dyskinesis in young bowed string instrumental musicians
}

\author{
Antonio Frizziero ${ }^{1}$ \\ Giuseppe Gasparre ${ }^{1}$ \\ Serena Corvo ${ }^{1}$ \\ Jacopo Gamberini ${ }^{1}$ \\ Paolo Finotti ${ }^{1}$ \\ Stefano Masiero ${ }^{1}$ \\ Nicola Maffulli ${ }^{2}$
}

1 Department of Physical and Rehabilitation Medicine, University of Padua, Italy

2 Department of Musculoskeletal Disorders, University of Salerno, Salerno, Italy; Queen Mary University of London, Barts and The London School of Medicine and Dentistry, Mile End Hospital, London, England; Institute of Science and Technology in Medicine, Keele University School of Medicine, Stoke on Trent, England

\section{Corresponding author}

Antonio Frizziero

Department of Physical and Rehabilitation Medicine,

University of Padua

Via Giustiniani 2

35128 Padova, Italy

E-mail: antonio.frizziero@unipd.it

\section{Summary}

Introduction: Instrumental musicians impose intense and repetitive strains on the musculoskeletal system. This makes them particularly susceptible to musculoskeletal disorders, especially at the spine and the scapular girdle, including scapular dyskinesis. The present study evaluated the presence of incorrect posture and scapular dyskinesis in young musicians playing bowed string instruments.

Methods: We recruited 32 young adult students of the Music Academy "Conservatorio C. Pollini" of Padua, including 14 violinists, 3 violists, 10 cellists and 5 double bass players. Scapular dyskinesis was assessed with a specific test, which involves the repetition of shoulder abduction and flexion movements with dumbbells weighting 1 and $2 \mathrm{~kg}$. The spine was assessed using a headband with compass mechanism (IncliMed ${ }^{\circledR}$ ) and a gibbometer. Results: Scapular dyskinesis was identified in
$46.9 \%(\mathrm{~N}=15)$, hyperkyphosis in $34.8 \%(\mathrm{~N}=11)$, and a hump in $37.5 \%(\mathrm{~N}=12)$ of the subjects. The association between hump and weekly hours of practice was statistically significant $(p<0.05)$, as well as the association between the presence of a hump and hyperkyphosis $(p=0.05)$.

Conclusions: Bowed strings instrumental musicians exhibit changes in static and dynamic posture of the shoulder girdle and spine. Such alterations could lead to the onset of postural asymmetries (hyperkyphosis), the onset and/or worsening of underlying and unrecognized conditions such as scoliosis, and the impairment of normal biomechanics resulting in the appearance of scapular dyskinesis.

Level of evidence: III.

KEY WORDS: scapular dyskinesis, string instrument, musicians, hyperkyphosis.

\section{Introduction}

Instrumental musicians perform intense and repetitive movements and expose themselves to developing musculoskeletal conditions, particularly in the shoulder girdle and spine ${ }^{1}$.

Playing related musculoskeletal disorders (PRMDs) are present in up to $86 \%$ of instrumental musicians ${ }^{2}$. These disturbances involve particularly the shoulder (20\%) and the cervical (22\%) and the lumbar spine $(20 \%)^{3}$. Epidemiologically, there are no differences in the disturbance rate between professional musicians and young music students, while females seem to be at greater risk, especially after menopause ${ }^{4}$. Playing a bowed string instrument is a major risk factor for the development of PRMDs ${ }^{5}$.

In the kinetic chain composed of the humerus and upper extremity on the one hand, and trunk and spine on the other, the scapula acts as a link.

Physiologically, the shoulder position, the muscle and joint stability and the control of upper extremity movements depend on scapular performance ${ }^{6}$.

Over the last few years studies on scapular motion in healthy subjects defined scapulo-humeral rhythm and muscular forces involved 7,8 . Three-dimensional motion analysis and bi-planar fluoroscopy accurately describe patterns and amplitudes of movements and provide reference parameters for the scapular movement ${ }^{9-11}$. Such knowledge represents the substrate to determine normal and altered positions and scapular movements. 
The presence of noticeable alterations in scapular position and/or in its movement patterns in relation to the rib cage is defined as scapular dyskinesis ${ }^{12}$. Scapular dyskinesis is not well-defined ${ }^{13}$; it could be related to various conditions altering the relationship between the glenohumeral and acromioclavicular joints, or which act on correct muscle activation and coordination ${ }^{14}$. As the clinical presentation is variable, it is difficult to estimate the exact rate of scapular dyskinesis. A high incidence has been found in people who play sports such volleyball and baseball, which involve overuse of the upper extremity with repetitive movements of scapulo-humeral and scapulo-thoracic joints ${ }^{15-17}$.

A total of $54 \%$ of music students present anteposition of the head, asymmetries of shoulders and pelvis, thoracic hyperkyphosis, scoliosis and lumbar lordosis ${ }^{18}$. Prolonged holding of the same forced posture, playing an instrument overloads the musculoskeletal system ${ }^{19-22}$. Maintaining the correct posture while playing music is mandatory, not only to avoid musculoskeletal overload, but also to play music appropriately. The correct balanced posture for a musician is the position in which the pelvis and spine are properly aligned to perform correctly the movements necessary for playing. The right balanced position is crucial to adequately support the shoulder and allow the arms to move correctly.

Bowed string instruments include violin, viola, cello and double bass. The present study focuses on young musicians who play these instruments to evaluate the presence of incorrect posture and scapular dyskinesis.

\section{Materials and methods}

The local Ethical Committee of the University of Padua approved this study (ref. 62005) and all the procedures conformed to the Declaration of Helsinki.

All bowed string instrument students at the C. Pollini Conservatory (Padua, Italy) were examined. Subjects with pre-existing orthopedic, rheumatic and neurological conditions which could have compromised the proper conduction of tests, were excluded from the study. Finally, thirty-two (27 females and 5 males; average 20.8 years, range 15 to 32 ) students met the inclusion criteria and all of them accepted to be enrolled in this study. The group included 14 violinists, 3 violists, 10 cellists and 5 double bassists. Each subject or their parents signed the informed consent form.

The students had been playing for an average of 8.9 (range 3 to 15) years. The average number of practice hours per week was 22.7, ranging from 7 to 55 .

Clinical evaluation of the participants included medical history, a general physical examination, study of the shoulder and evaluation of the spinal.

The parameters collected were: age, gender, height, weight and BMI, sport activity. The presence of previous trauma (with special interest to those located in the upper extremities and spine) and whether scoliosis had previously been diagnosed and eventually treated was also investigated. During the interview, data on musical activity were collected: instrument(s) played, number of years the students had been playing, and number of hours of practice per week.

The whole spine was evaluated. The cervical spine was examined for the presence of cervicalgia and/or muscle contractures by inspection and palpation. Afterwards, the range of active motion (ROM) of this segment was studied with the use of an analog helmet allowing to measure flexion-extension, leaning to the right and left, left and right rotation. Clinical examination of the dorsolumbar spine began with inspection and palpation to evaluate the presence of dorsal pain and/or lumbago or muscle contractures ${ }^{23,24}$. Next, for the dorso-lumbar spine the range of active movement was also evaluated for flexion-extension movements and leaning to the right and left side, by using a Protractor or circular pocket inclinometer with a compass mechanism (IncliMed®, patent No. 0001331516 , University of Padua) 25,26 .

The clinical examination of dorso-lumbar spine was concluded with the evaluation of any hump, using a gibbometer which measures the difference between concavity and convexity of the curve ${ }^{27}$. To measure the hump with a gibbometer, the patient was asked to bend forward as much as possible while keeping his knees straight and arms loose (forward bending test). The instrument was then rested at the height of the hump, determined earlier by the operator, by picking the point with the greatest difference between left and right side. All patients were evaluated using the Costant-Murley Score ${ }^{28}$ and underwent specific clinical tests to highlight the presence of one or more of the main disorders of the shoulder.

Muscle strength was tested in individual movements of the upper extremity: flexion, extension, abduction, adduction, internal rotation, external rotation. For each movement a score from 0 to 5 was assigned, where 0 meant absence of muscle strength and 5 presence of preserved muscle strength.

Clinical examination of the shoulder was concluded with a test for scapular dyskinesis. The test consisted of 5 repetitions of bilateral, active, weighted shoulder flexion and bilateral, active, weighted shoulder abduction (coronal plane).

Flexion and abduction testing was performed with the student holding a dumbbell in each hand. Subjects with body weight up to $68 \mathrm{~kg}$ used $1 \mathrm{~kg}$ dumbbells, while subjects weighting more than $68 \mathrm{~kg}$ used $2 \mathrm{~kg}$ dumbbells (Fig. 1).

Video recordings were made with a commercially available camera (Exilim Ex-Z30, Casio, Tokyo, Japan).

Each movement pattern (bending and abduction) was evaluated as: normal movement; slight abnormality; defined as slight or obvious abnormality not consistently present; severe abnormality; when present in at least 35 repetitions (expressed as a dysrhythmia or a lifting of the medial scapular border above $2.5 \mathrm{~cm}$ ). The final score was based upon a combination of flexion and abduction movements.

Scapular movement was classified as: normal (both tests were evaluated as normal or one movement is evaluated as normal and the other as slightly abnor- 


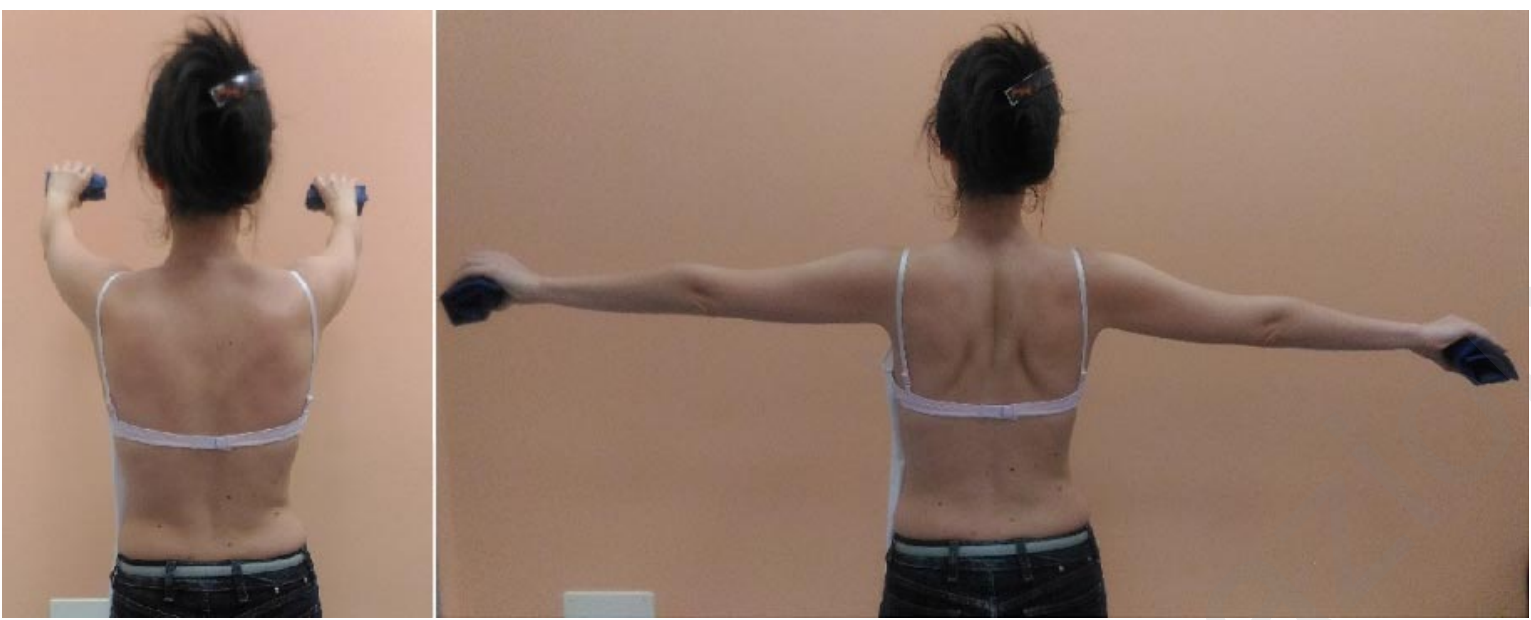

Figure 1. Young musician performing bilateral, active, shoulder flexion (left image) and abduction (right image) with $1 \mathrm{~kg}$ dumbbells.

mal); slightly abnormal (both movements are evaluated as slight or uncertain abnormality); abnormal (one of the two movements is evaluated as severe abnormality).

Evaluation was performed during the test and by evaluating the video.

\section{Statistical analysis}

The demographic characteristics of patients have been reported for each subject as number and percentage of patients in each category for categorical variables. The distribution of the variables was analyzed using the Student's t-test, setting significance at $5 \%(p<0.05)$. Statistical analysis was conducted with SAS program 9.2 (SAS Institute Inc., Cary, NC, USA) for Windows.

\section{Results}

Humps were identified in $37.5 \%(\mathrm{~N}=12)$ of subjects $(\mathrm{Cl}$ $35.1-93.5)$. The rate of hyperkyphosis in the same sample was $34.4 \%(\mathrm{~N}=11)(\mathrm{Cl} 30.6-88.4)$, while the rate of scapular dyskinesis was $46.9 \%(\mathrm{~N}=15)(\mathrm{Cl} 29.1-65.3)$.
Dividing the sample based on the upper extremity side involved (right or left), on their right side 2 subjects $(6.2 \%)$ exhibited slight scapular dyskinesis, and 2 subjects $(6.2 \%)$ showed obvious signs of dyskinesis. On their left side, slight scapular dyskinesis increased up to $31.2 \%$ (10 subjects), while the percentage of obvious scapular dyskinesis remained constant (Fig. 2).

Humps were present in $66.7 \%(\mathrm{~N}=8)$ of subjects who played their instrument for more than 21 hours/week, compared to $20 \%(\mathrm{~N}=4)$ in subjects who played for 21 hours or less per week. The cut-off limit of 21 hours/week was chosen as it was the median of hours spent playing music in our sample.

Hyperkyphosis was evident in $66.7 \%(\mathrm{~N}=8)$ of subjects with a hump, while in subjects without hump $25 \%(\mathrm{~N}=5)$ had hyperkyphosis.

According to the type of instrument played, $60 \%(\mathrm{~N}=3)$ of double bassists, $41.2 \%(\mathrm{~N}=7)$ of violinists and violists, $10 \%(\mathrm{~N}=1)$ of cellists had hyperkyphosis.

A total of $60 \%(\mathrm{~N}=3)$ of double bassists, $35.3 \%(\mathrm{~N}=6)$ of violinists and violists and $30 \%(\mathrm{~N}=3)$ of cellists exhibited scapular dyskinesis on the left side, while $17.5 \%$ $(\mathrm{N}=3)$ of violinists and violists and $10 \%(\mathrm{~N}=1)$ of cellists exhibited it on the right (Figs. 3, 4).

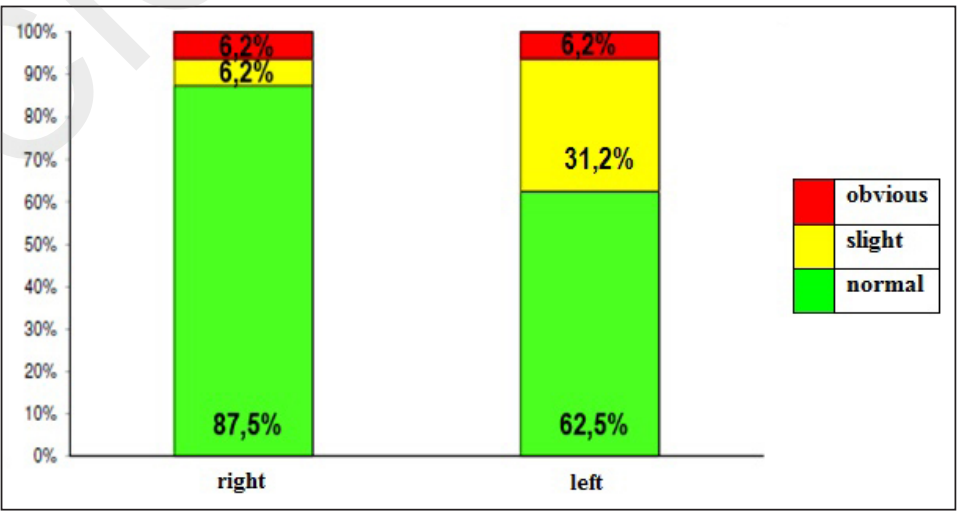

Figure 2. Prevalence of scapular dyskinesis according to the side. 


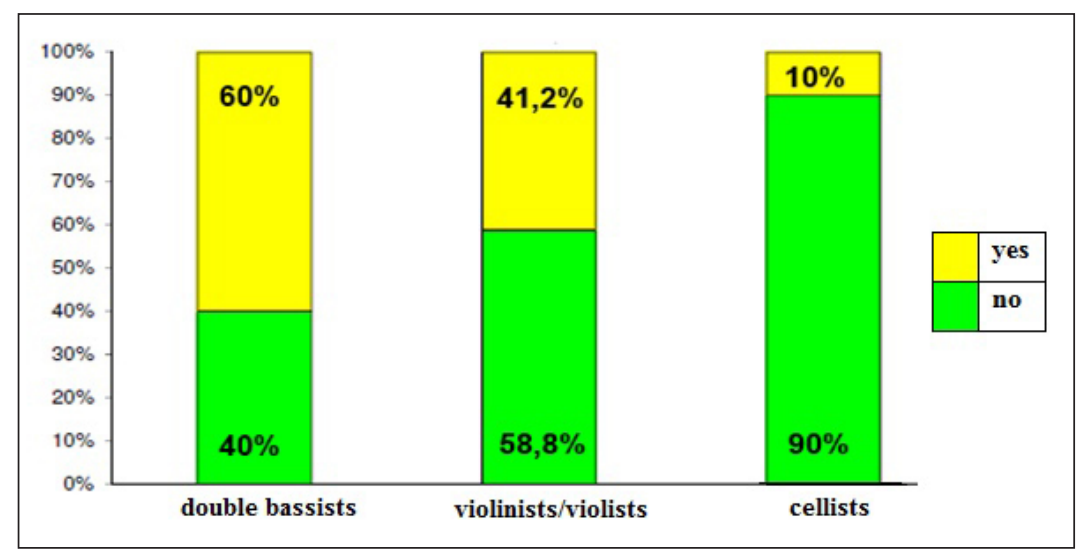

Figure 3. Prevalence of hyperkyphosis according to type of bowed string instrument.

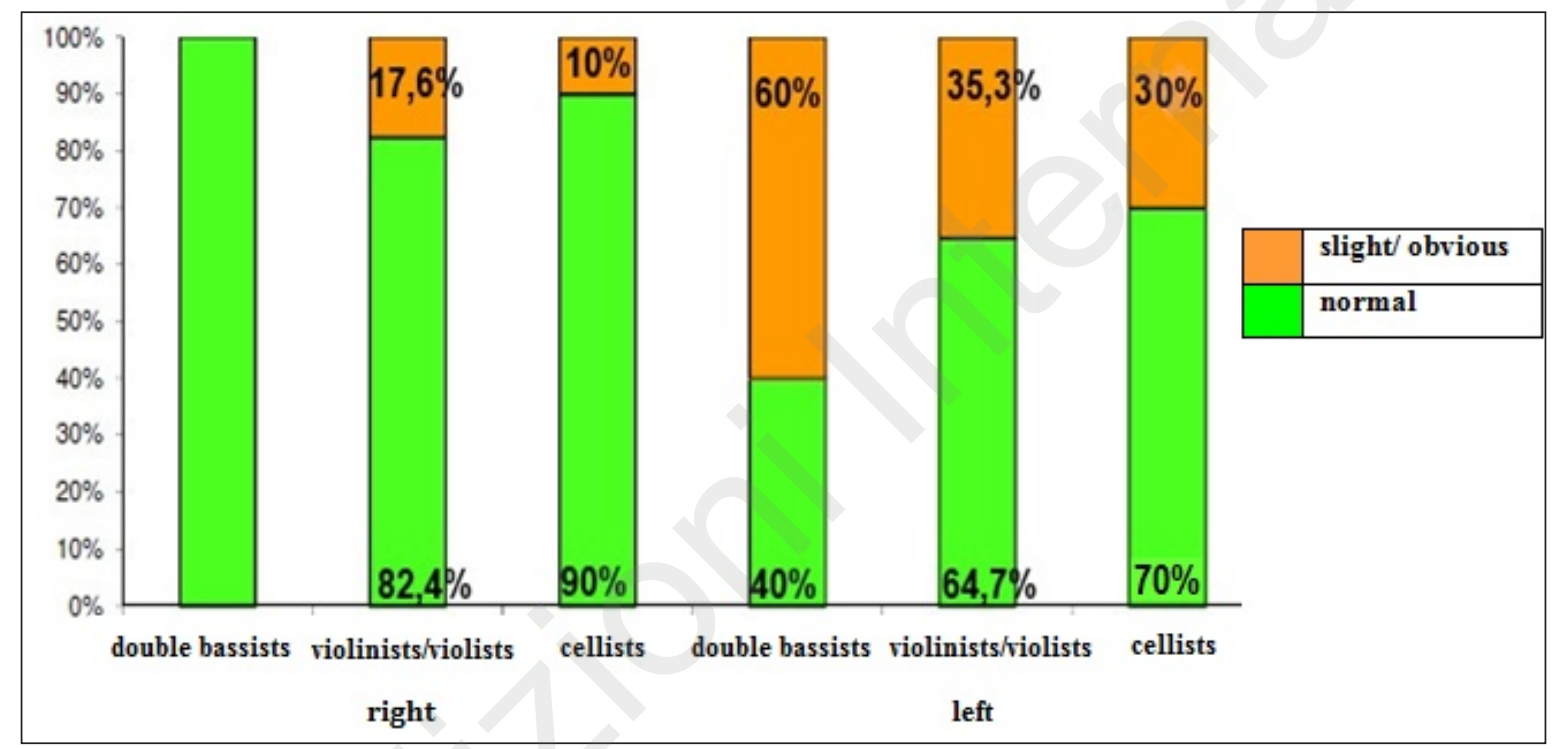

Figure 4. Right and left scapular dyskinesis according to type of bowed string instrument.

\section{Discussion}

Scapular and spine alterations, particularly of the thoracic spine, were prevalent in the young musicians enrolled in the present study: scapular dyskinesis was identified in $47 \%$ of them.

Scapular dyskinesis was more frequent on the left in all the three categories of musicians. This is particularly true in double bassists, for whom the rate of dyskinesis was $60 \%$ on the left, with no signs of it on their right side. This higher rate of left scapular dyskinesis may be explained considering that the left shoulder and arm are subjected to prolonged static posture, as they support the instrument, while the left hand moves the bow and the left fingers depress the strings ${ }^{29}$. The right hand slides the bow on the strings. Double bassists in particular are inclined to twist their spine to the left, especially when playing on the $G$ string (closer to the body) or while raising their hand near the neck of the instrument. In this position, or if the back is arched, keeping the correct posture between the left scapula and the thoracic wall is extremely difficult. This affects muscles supporting the scapula, with consequent fatigue of the trapezius, serratus anterior and the rotator cuff muscles.

Comparing the rates of scapular dyskinesis in the three types of bowed string instrument students, the higher prevalence on the left is less accentuated in cellists, although it would be expected to be comparable to the rate of double bassists. Since the cello is smaller than the double bass but bigger than the violin and viola, in cellists the extent and rate of the alteration may be proportionally less than in double bassists. However, the shape of the instruments involved is fundamental. In fact, playing the cello requires being seated, thus allowing the spine to retain its physiological curvature, with more relaxed muscles, both at lumbar and thoracic level. A similar trend is present in the rate of hyperkyphosis. The double bassists are the most affected category $(60 \%)$, followed by violinists and violists $(41.2 \%)$ and cellists (10\%).

These findings may be explained by the posture kept 
while playing the different instruments. While playing, double bassists tend to horizontally adduct their pelvis, thus affecting all the curves in the spine: a reduction of lumbar lordosis causes an increase in thoracic hyperkyphosis and vice versa. Short double bassists or those with shorter arms are more prone to such horizontal adduction of the pelvis.

The violin and viola can be played either seated or standing up. The seated position determines in the violinist or violist horizontal adduction of the pelvis with reduction of the lumbar curve and simultaneous accentuation of the thoracic curve. This requires greater effort by the extensor muscles of the spine, and affects the muscles stabilizing the scapula. Their fatigue may determine furthering of the scapula from the chest wall and consequent scapular dyskinesis.

The presence of a hump shows evidence of a statistically significant positive association with the number of hours per week spent playing music. In particular, considering 21 hours/week the reference cut-off limit (representing the median of hours per week our sample spent playing music), two thirds of those playing for more than 21 hours/week presented a hump, and 20\% of those who played for less than 21 hours per week had a hump. The hump is a clinical sign of scoliosis. In our study, in conformity to the Italian Guidelines for the treatment of scoliosis, a thoracic or thoracic-lumbar hump equal to or higher than $5 \mathrm{~mm}$ is considered clinically significant.

The association between the presence of a hump and prolonged music playing may be explained by considering the presence of unrecognized scoliosis, which can be exacerbate by prolonged practice, given the postural implications described.

Furthermore, two thirds of subjects with a hump also showed signs of hyperkyphosis, which was present in $25 \%$ of subjects without a hump. The hyperkyphosis found in our sample was postural, and self-correction was possible. The association between hyperkyphosis and a hump ( $p=0.0529)$ may be once again explained considering the type of asymmetrical posture adopted.

\section{Conclusions}

Playing musical instruments repeatedly for a long period of time may cause static and dynamic alterations of the shoulder girdle and spine. These alterations may induce postural asymmetries (hyperkyphosis), stabilization and exacerbation of underlying scoliosis and the impairment of normal scapular biomechanics with the onset of dyskinesis.

The prevalence of scapular dyskinesis and hyperkyphosis is associated with the bowed string instrument played, and to the posture required to play.

On the contrary, the presence of a hump does not depend on the type of instrument, but on the number of hours per week spent playing music, indicating that prolonged and not properly controlled playing can lead to underlying alterations to the axial skeleton. A similar evaluation is needed on professional musicians to veri- fy the effects of playing musical instruments for a long time on older subjects.

\section{Compliance with ethical standards}

\section{Conflicts of interest}

The Authors declare no conflicts of interest.

\section{Ethics}

The Authors declare that this research was conducted following basic ethical aspects and international standards as required by the journal and recently update $\mathrm{in}^{30}$.

\section{References}

1. Joubrel I, Robineau S. Pathologies de l'appareil locomoteur du musiciens: étude epidemioloque. Med Phys. 2001;44:72-80.

2. Steinmetz A, Seidel W, Muche B. Impairment of Postural Stabilization System in Musicians with Playing-Related Muscoloskeletal Desease. J Manipulative Physiol Ter. 2010; (10):603-610.

3. Fishbein M, Middlestadt S, Ottati V, Straus S, Ellis A. Medical problems among ICSOM musicians: overview of a national survey. Med Probl Perf Art. 1988;3:1-8.

4. Van Eijsden-Besseling M, Kuijers M, Kap B, Stam H, TepstraLindemann E. Differences in posture and postural disorders between music and medical students. Med Probl Perf Art. 1993:8:110-114, 107.

5. Zaza C. Playing-related muscoloskeletal disorders in musicians: a systematic review of incidence and prevalence. CMAI. 1998;158:1019-1025.

6. Kibler WB, Sciascia AD, Wilkes T. Disorders of the scapula: winging and snapping. In press, lannotti JP, Williams GR, eds. Diagnosis of the shoulder: diagnosis and management. Vol. $3^{\text {rd }}$ edn. Philadelphia: Lippincott Williams and Wilkins. 2013.

7. Inman VT, Saunders JB, Abbott LC. Observations of the function of the shoulder. Clin Orthop Relat Res. 1996;330:3-13.

8. Bagg SD, Forrest WJ. A biomechanical analysis of scapular rotation during arm abduction in the scapular plane. Am J Phys Med Rehabil. 1988;67:238-245.

9. Lukasiewicz AC, McClure P, Michener L, et al. Comparison of 3- dimensional scapular position and orientation between subjects with and without shoulder impingement. J Orthop Sports Phys Ther. 1999;29:574-586.

10. McClure PW, Michener LA, Sennett BJ, et al. Direct 3-dimensional measurement of scapular kinematics during dynamic movements in vivo. J Shoulder Elbow Surg. 2001;10:269-277.

11. Giphart JE, van der Meijden OA, Millett PJ. The effects of arm elevation on the 3-dimensional acromiohumeral distance: a biplane fluoroscopy study with normative data. J Shoulder Elbow Surg. 2012;21:1593-1600.

12. Kibler WB, McMullen J. Scapular Dyskinesis and Its Relation to Shoulder Pain. J Am Acad Orthop Surg. 2003;11:142-151.

13. Wright $A A$, Wassinger $C A$, Frank $M$, et al. Diagnostic accuracy of scapular physical examination tests for shoulder disorders: a systematic review. Br J Sports Med. 2013 Sep; 47(14):886892.

14. Kibler WB, Ludewig PM, McClure PW, Michener LA, Bak K, Sciascia AD. Clinical implications of scapular dyskinesis in shoulder injury: the 2013 consensus statement from the 'scapular summit'. Br J Sports Med. 2013;47:877-885. 


\section{A. Frizziero et al.}

15. Merolla G, De Santis E, Campi F, Paladini P, Porcellini G. Infraspinatus Scapular Retraction Test: a reliable and pratical methot to assess infraspinatus strenght in overhead athletes with scapular diskinesis. J Orthopaed Traumatol. 2010;11: 105110.

16. Merolla G, De Santis E, Campi F, Paladini P, Porcellini G. Sopraspinatus and Infraspinatus weakness in overhead athletes with scapular diskynesis: strenght assessment before and after restoration scapular muscolature balance. Muscoloskelet Surg. 2010;94:119-125.

17. Ellenbeker TS, Kibler WB, Baillie DS, Caplinqer R, Davies GJ, Reimann BL. Reliability of scapular classification in examination of professional baseball players. Clinical Orthop Relat Res. 2012 Jun;470(6):1540-1544.

18. Van Eijsden-Besseling M, Kuijers M, Kap B, Stam H, TepstraLindemann E. Differences in posture and postural disorders between music and medical students. Med Probl Perf Art. 1993;8:110-114, 107.

19. Frank AO, Maddison PJ. Work and the muscoloskeletal conditions. Clin Med. 2004;4:362-365.

20. Bejjiani FJ, Kaye GM, Benham M. muscoloskeletal and neuromuscolar conditions of instrumental musicians. Arch Phys Med Rehabil. 1996;77:406-413.

21. Zaza C. Playing-related muscoloskeletal disorders in musicians: a systematic review of incidence and prevalence. CMAI 1998;158:1019-1025.

22. Birczyk-Pawelec K, Sipko T, Demczuk-Wodarczyk E, Boczar A. Anteroposterior Spinal Curvatures and Magnitude of Asymmetry in the Trunk in Musicians Playing the Violin compared with Nonmusicians. J Manipolative Physiol Ther. 2012;35: 319-326.

23. Aulisa L, Bartolini F, Tamburelli F, Valassina A. La scoliosi: la diagnosi precoce mediante screening nelle scuole. Atti del Convegno S. Maria della Pietà, Roma. 1981:1-26.

24. Aulisa L, Bartolini F, Tranquilli Leali P. La familiarità nella scoliosi idiopatica: studio statistico e considerazioni cliniche. Arch Ortop Reumatol. 1982;95:111-122, 109.

25. Ferraro C, Gottardo A. La misurazione del gibbo: studio critico mediante un dispositivo tascabile. Minerva Ortopedica e Traumatologica. 1993;44:637-643.

26. Grosso C, Paroli C, Cabitza P, Negrini S. Ripetibilità e accuratezza della rotazione assiale del tronco e dell'altezza del gibbo: uno studio clinico. Giornale Italiano di Medicina Riabilitativa. 2002;8(5):65.

27. Ensrud KE, Black DM, Harris F, Ettinger B, Cummings SR. Correlates of kyphosis in older women. The Fracture Intervention Trial Research Group. J Am Geriatr Soc. 1997;45:682-687.

28. Constant CR. Cork: MCH Thesis. University College; 1986. Age related recovery of shoulder function after injury.

29. Takahashi T, Ishida K, Hirose $D$, et al. Trunk deformity is associated with a reduction in outdoor activities of daily living and life satisfaction in community-dwelling older people. Osteoporos Int. 2005;16:273-279.

30. Padulo J, Oliva F, Frizziero A, Maffulli N. Muscles, Ligaments and Tendons Journal - Basic principles and recommendations in clinical and field science research: 2016 update. MLTJ. 2016;6(1):1-5. 